although the physical principles being known this work might be held to have passed into the province of the engineer. However, the mathematical functions are generally intractable, and engineers may be excused for their reliance on methods of trial and error. As valves get larger, however, such methods are becoming expensive. The evolution of the valve is not yet by any means complete, although sometimes, as in television, the valve is an accepted tool and interest centres on other devices at either end of the train of valves.

There is still, however, the new field where the periods of electrical oscillation are so short that electron inertia is no longer negligible, but has itself to be brought into service as a main principle of action. Here early history has been repeating itself, but the period of groping is now past; theoretical study is difficult but is well advanced. Indeed, in contrast to the early days, development has been somewhat in advance of demand. There are also novel devices using free electrons which are not of thermionic origin but are ingeniously obtained by photo-electric or secondary emission.

Other new developments may be expected now that valves have made their appearance in the laboratory as appliances built and operated by continuous evacuation in the laboratory for the purposes of research without recourse to the valve maker, for example, for obtaining continuous high- voltage supplies by rectification and very recently also by short-wave oscillation. It is not in general to be supposed that valves manufactured by the thousand for engineering purposes or by the million for domestic use are really those best suited for special problems, and it is well that the experimental physicist should take the initiative in meeting his own needs.

Finally, new prospects are beginning to open in yet other directions associated rather with the material needs of the human body than with man as an intelligent and social being. For some few years high-frequency electrical oscillations of wave-lengths from a few metres downwards generated by valves have been coming into use for purposes as yet perhaps of practical medicine rather than of physiological study, first for surgery, and later for the reinforcement of the vis medicatrix naturce, in part, it would seem, by some kind of inward fomentation, and in part, perhaps, by some more specific action dependent on the existence of natural frequencies in molecules of various sizes or in small bodies of greater than molecular size. The achievement of direct specific action on such structural elements would open up wide fields of application to chemical and biological processes far removed from the problems of communication from which the development of the essential instrument took its origin.

\title{
Developments in Aeronautical Science
}

\author{
By Prof. F. T. HrLl, Assistant Professor of Aeronautics, Imperial College of Science \\ and Technology, London
}

$\mathrm{T}$ HERE can be few applied sciences able to compare with aviation in the rate at which purely academic physical conceptions have been first translated into actual accomplishments and then industrialised, to the extent of the aircraft industry in the short space of a quarter of a century. Although the mechanics of flight have been investigated by certain mathematicians practically since the Middle Ages, continuous sustained flight for heavier-than-air machines, or even a useful degree of controlled flight in lighterthan-air craft, was not possible until some device capable of giving out power in the form of a propeller thrust was available, with reasonable weight. The internal combustion engine made this possible, and in 1903 the first power-driven flight in a heavier-than-air machine was made by one of the Wright brothers in the United States. The dirigible balloon antedated this achievement by a few years for lighter-than-air craft, although it is not possible to be precise about the date of the first flight owing to the difficulty of specifying exactly what constituted a power-driven flight, as distinct from having merely floated from one spot to another. It is certain, however, that at the commencement of the period under review, achievement in either school did not consist of much more than having succeeded in flying for a reasonable period of time, with a very small margin of safety. Little attention had been paid to progress towards any severely utilitarian aspects of the problem of flight.

In the spring of 1910, Cody, Dunne, Roe and Short were flying aeroplanes of their own design and building in Great Britain. Mr. J. T. C. MooreBrabazon (now Lieut.-Col. and at present president of the Royal Aeronautical Society) was granted 
the R. Ae. C. Club pilot's certificate number one, for making the first officially observed flight in the British Isles, under certain specified conditions. The power used varied from a 50 horsepower Antoinette in Cody's machine to a 9 horsepower J.A.P. engine used by Roe. Speeds appear to have been about 50-55 miles per hour, and somewhat uncertain, but Cody held one definite record then of having remained in the air for a little more than one hour.

With lighter-than-air craft, the pressure type of envelope was in use then. This was either non-rigid, using the gas pressure to maintain its elongated form, or semi-rigid, with the shaped balloons partly stabilised and supported by a longitudinal framework. Airship activity in Britain was almost entirely confined to the British Army Balloon Factory at Farnborough. A few small airships were built by Messrs. Willows and Co. during the years 1905-12, an outstanding feature of these being the introduction of swivelling propellers as an auxiliary to the normal controlling surfaces, a device still often used on modern airships. The Army airships of early 1910 were capable of about 35 miles per hour speed, with a 35 horse-power Green engine, and carried a crew of three.

The period 1910-18 can logically be considered to be one of the development of war machines. Previous to 1914, the production of machines directed towards a military outlook was stimulated by a War Office competition held in the summer of 1912, and as no equal incentive towards any form of civil aviation existed, the military requirements predominated in design then. The year 1912 thus crystallised the attainments of the machines of that day in the military competition, and helped to give definite ideas upon possible lines of improvement. A top speed of 75 miles per hour, a lowest speed of 50 miles per hour necessarily accompanying it, a rate of climb of about $400 \mathrm{ft}$. per minute, and a ratio of descent to forward travel with the engine stopped (gliding angle) of 1 in 8 , can be taken to be the best performances then. Military requirements demanded increase in top speed and climb for fighting purposes, an increased gliding angle for enlarging the area over which the pilot could land in the event of engine failure, and a reduction, if possible, in the already dangerously high landing speed. The development during the whole War period can be summed up by saying that the required improved performances were obtained by the use of greater and greater powers, as these became available from contemporary improvement in the internal combustion engine designed specifically for aircraft work. By 1918 these average values (excluding a few freaks for special purposes) can be said to have reached 130 miles per hour for top speed without any corresponding increase in landing speed, 2,000 ft. per minute for initial rate of climb, and a gliding angle, although varying considerably with the type of machine, greater than 1 in 8 . Size had also increased from a two-seater, say, $500 \mathrm{lb}$. total useful load, to one carrying a load of about $9,000 \mathrm{lb}$.

During this same period the most marked advance in the lighter-than-air craft was that of size, which brought about the necessity for a different construction, the 'Rigid' or Zeppelin type. In this a number of separate gas bags are encased in a rigid framework of elongaged cylindrical form, the whole of the load being taken by this structure. This construction is used for all large airships to-day. The smaller airships were by no means superseded, but they made no great strides in development, being suited to the naval and military duties allotted to them without any drastic alterations. By 1918, British rigid airships had reached a speed of 70 miles per hour, carried 1,250 h.p. in power, with a disposable load of about 27 tons. The most outstanding point in performance, in which the airship is still ahead of the aeroplane, was its range. At a reduced speed of 45 miles per hour, the rigid airship of that day had a cruising range extending over nearly nine days.

The reconstruction period in 1919 allowed attention to be paid to the more scientific side of aircraft design, when the immediate urgency of increased performance at all costs was removed. The study of aerodynamic theory produced rules for design resulting in less resistance to motion, both from drag and interference, the net result of which was either increase of speed, greater carrying capacity or wider range, for a given engine-power output. Progress in engine development itself gave that power with less engine weight, smaller fuel consumption, and reduced drag for cooling purposes, and concurrently engines of greater power were produced. A better understanding of the problem of aerodynamics and theory of structures, added to the increased engine-powers available, led heavier-than-air craft design into specialised channels, and types tended to become, and have remained, with different characteristics depending upon their design criterion. To-day the records stand at 440.67 miles per hour maximum speed, 5,654 miles non-stop distance, and more than $57,000 \mathrm{lb}$. useful load carried. In none of these cases are such machines of any general use, but the figures indicate the magnitude of the progress made during the post-War period. A fair estimate of how far practical requirements modify these figures is obtained if the results of the England. 
Australia race of October 1934 are taken. This was won by a De Havilland Comet which, although built specially for the race, is of a type that could be used for ordinary everyday commercial flights. The flight to Australia, a distance of 11,300 miles, occupied 60 hours 50 minutes flying time, an average not far short of 200 miles per hour. Certain military types have normal speeds somewhat higher than this.

That such progress should have been made without setbacks is scarcely to be expected, and it is almost paradoxical that such failures, resulting in a train of investigations into their causes, have probably been the greatest help to ultimate success. The investigation of accidents and the subsequent building up of design laws that shall avoid a repetition of them, has been one of the responsibilities of the Aeronautical Research Committee in Great Britain throughout the whole of the period under review. For example, the gradual increase in speed has produced aerodynamic forces on the wings the precise extent of which had not been anticipated from the experience available at lower speed flight. The current theory of structural design was not always adequate to deal with such cases, and wings and control surfaces, lacking stiffness, have developed 'flutter' which has sometimes led to the collapse of the structure of the aircraft. It can be safely said that to-day the scientific aspect of this question has now been worked out.

Another similar outstanding scientific development is that of landing a machine with maximum safety. As the top speed of flight began to increase, it became necessary to investigate the aerodynamics of increasing the speed range, otherwise the landing speed became dangerously high. Even with this as low as possible, pilots are tempted into approaching too near it, and with no margin in hand, they allow the machine's speed to fall below the minimum, and 'stall', usually with serious results. This problem has been defeated in two distinct ways: the use of aerodynamical devices that delay the occurrence of the 'stall' to a slower speed, or giving the pilot that extra control over the orientation of the machine by which he can neutralise the most dangerous result of a 'stall', the loss of his normal control actions. A combination of these two ideas to-day can make the actual flying of a machine as nearly 'foolproof' as can ever be needed. One attempt at dealing with this question has resulted in the creating of a novel type of aircraft-the autogiro. The supporting wings of this machine are rotated in a horizontal plane, windmill fashion, instead of being fixed to the body, as in the normal form of aeroplane. Thus, their lift, which supports the machine, depends primarily upon their speed of rotation and not upon the forward speed of the craft. This latter may be reduced very greatly by the pilot, but as long as the wings are kept rotating above the minimum speed necessary, the machine will retain its full support.

The post-War history of lighter-than-air craft is unfortunately not so happy a tale. The rigid airship has grown in size, and has been developed towards the idea of a long-distance transport machine. A new German Zeppelin, just about to be launched, will carry eighty-five passengers, ten tons of freight, in addition to accommodation almost comparable with an Atlantic liner. Its engines total 5,000 horse-power, and its range without refuelling will be about 10,000 miles. This ship, together with a somewhat smaller sister, the Graf Zeppelin, now flying regularly, will be the only large rigid airships in commission in the world. The generally accepted principle of any vessel that obtains its lift from buoyancy - that its efficiency as a load carrier increases with its dimensionsmeans that the accompanying increase in cost makes the experiments more susceptible to the difficulties of replacement in the case of failures. Both Great Britain and the United States have discontinued experiments upon large rigids, largely because of the political aspect that has arisen as the result of accidents costly both in lives and material.

To sum up the situation to-day, after twentyfive years development, in heavier-than-air craft any speeds, up to those that the ordinary human being can stand without special training, can be flown, provided that the price in power required for it can be paid. This price will probably be reduced gradually as more efficient machines are produced, but there does not appear to be any very revolutionary change in sight. Sizes of machines such as will give a reasonable degree of comfort are already in existence, and will probably increase, although in theory there should be a limit to this, as the ratio of the structural weight of the machine to the total flying weight must increase. This limitation is not serious so long as the size necessary for comfort has been attained. In range it is still uncertain as to whether the direct route across the Atlantic and Pacific Oceans can be flown under unfavourable conditions, at least as an economic proposition. Except for these two cases, the range of any normal aeroplane can be such that it is well within reach of organised aerodromes all over the civilised world. In this last case lies the principal hope for the future of the large airship. Its capacity is such that the longest possible journey necessary, that is, halfway round the earth, is probably within its attainments even to-day. 